\title{
Effect of Selenium Supplementation in Broiler Diets on Breast Meat Deposition
}

http://dx.doi.org/10.1590/1806-9061-2019-1142

\section{-Author(s)}

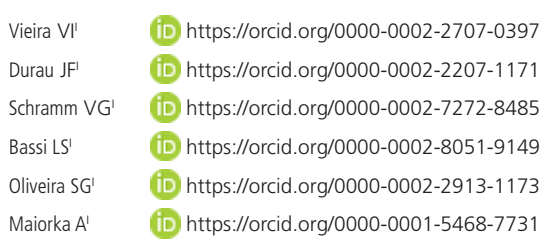

Department of Animal Science, Federal University of Paraná, Curitiba, Brazil 80035-050.

\section{-Mail Address}

Corresponding author e-mail address Simone Gisele de Oliveira

Universidade Federal do Paraná -

Departamento de Zootecnia - Curitiba, PR,

Brazil, Code 80035-050.

Phone: +55 41 3350-5822

Email: sgoliveira@ufpr.br

\section{EKeywords}

Breast muscle, hydroxy-selenomethionine, mineral deposition, sodium selenite.

\section{ABSTRACT}

The objective of the study was to evaluate the deposition of selenium in the breast muscle of broilers fed different selenium sources during different periods. Two experiments were carried out with broilers fed $45 \%$ sodium selenite (SS) or $2 \%$ hydroxy-selenomethionine (HSM) to determine the selenium deposition rate in the muscle tissue. In Experiment 1, 48 broilers were distributed in a completely randomized design with six treatments with eight replicates each, consisting of diets containing 0 Se (0), 200 or $400 \mu \mathrm{gSS} / \mathrm{kg}$ (200 SS, 400 SS), or 100, 200, or $300 \mu \mathrm{gHSM} / \mathrm{kg}(100 \mathrm{HSM}, 200 \mathrm{HSM}, 300$ HSM) for 10 days. The highest Se breast content was obtained with 300 HSM diet, followed by 200 SS diet compared to the other treatments. Experiment 2 had a completely randomized design following a plot scheme subdivided in time, and consisted of a basal diet supplemented with $300 \mu \mathrm{g} \mathrm{SS} / \mathrm{kg}$ (300 SS), basal diet with $200 \mu \mathrm{g} \mathrm{HSM} / \mathrm{kg}$ (200 HSM) or basal diet supplemented with $100 \mu \mathrm{gSS} / \mathrm{kg}$ and $100 \mu \mathrm{gHSM} / \mathrm{kg}(100 \mathrm{SS}+100 \mathrm{HSM})$. Dietary Se sources did not influence Se breast content measured on days 3 and 6 . However, on days 9 and 12, higher Se breast contents were measured in broilers fed $200 \mathrm{HSM}$ and 100 SS+100 HSM diets compared with those fed 300 SS diet. In conclusion, the supplementation of broiler diets with HSM at $2 \%$ for a short period is more efficient to increase selenium deposition in the breast muscle than sodium selenite.

\section{INTRODUCTION}

Selenium (Se) is considered an essential micronutrient in the diet of livestock, and an important component of the cellular antioxidant system. Selenium is part of the enzyme glutathione peroxidase, which catalyzes the reduction of hydrogen peroxide, a free radical, into oxygen and water (Szymonik-Lesiuk et al., 2003).

The consumption of Se food sources has several health benefits, such as preventing and ameliorating various types of cancer (Rayman, 2008), cardiovascular diseases (Cominetti et al., 2012), improving blood lipid profile by reducing LDL (low-density lipoproteins) levels and increasing HDL (high-density lipoproteins) levels (Colpo et al., 2013; Stockler-Pinto et al., 2015). The dietary reference intake (DRI) of Se recommended for adult men and women is $55 \mu \mathrm{g} /$ day $(I O M, 2000)$, and its main dietary sources are cereals, meat, and fish (Combs, 2001). The level of Se in food ingredients varies according to the conditions in which livestock were reared and to the composition of the soil where the plants were cultivated. Waegeneers et al. (2013) conducted a study in Belgium to investigate the level of selenium intake by the population and found that $31 \%$ is derived from meat or meat products.

In broiler feeds, Se is typically included in the trace mineral premix, which is added to the diets due to wide variation of trace mineral content 
Vieira V, Durau JF, Schramm VG, Bassi LS, Oliveira SG, Maiorka A
Effect of Selenium Supplementation in Broiler Diets on Breast Meat Deposition in the feedstuffs. Selenium is supplemented in either its inorganic forms, such as sodium selenite, or organic forms, which in general consist of seleno-amino acids. The main difference between organic and inorganic selenium sources is their bioavailability. FairweatherTait et al. (2010) reported that Se absorption as selenomethionine may be higher than $90 \%$, whereas sodium selenite reaches only $50 \%$.

Selenium deposition in muscle tissue is a reliable measure of the absorption efficiency of organic or inorganic Se sources in broilers, according to Briens et al. (2014). These authors also reported that these deposition rate depends not only on the dietary Se level, but also on its source, and demonstrated greater efficiency in the utilization of organic Se sources compared with sodium selenite in broilers.

The objective of this study was to evaluate the deposition of selenium in the breast muscle of broilers fed diets supplemented with an inorganic or organic Se source for different periods.

\section{MATERIAL AND METHODS}

The experiment was conducted in Curitiba, Brazil $\left(25^{\circ} 25^{\prime} 40^{\prime \prime} \mathrm{S}\right.$ and $\left.49^{\circ} 16^{\prime} 23^{\prime \prime} \mathrm{W}\right)$. The research on animals was approved by the Ethics Committee on the Use of Animals of Universidade Federal do Paraná.

\section{Birds, location and treatments}

A total number of 108 one-day-old male Cobb 500 broilers, obtained from a commercial hatchery, were housed in an experimental masonry shed, where environmental conditions were maintained according to the guidelines of the genetic company. In the first experiment, the shed was divided into six pens. Each pen was equipped with a tube feeder and two nipple drinkers and housed eight birds. In the second experiment, 12 pens, equipped as described above, housed five birds each.

The birds were submitted to the conventional management practices applied in Brazilian broiler commercial production. Regular basal diets were formulated to meet the broilers' requirements proposed by Rostagno et al. (2011) (Table 1) and offered in the pre-experimental period and contained $300 \mu \mathrm{g} \mathrm{Se} / \mathrm{kg}$ (Experiment 1) and 200 $\mathrm{gg} \mathrm{Se/kg} \mathrm{(Experiment} \mathrm{2).} \mathrm{Se} \mathrm{was}$ added as a separate ingredient in the form of sodium selenite ( $45 \%$ Se) during all feeding phases until the broilers reached 42 days of age. The premix did not contain any form of Se supplementation.
Table 1 - Ingredients and chemical composition of the experimental diets.

\begin{tabular}{lcc}
\hline Item & Experiment 1 & Experiment 2 \\
Ingredients (g/kg, as fed) & & \\
Corn & 696.6 & 663.4 \\
Soybean meal & 245.4 & 271.8 \\
Soybean oil & 32.2 & 38.8 \\
\hline Dicalcium phosphate & 6.8 & 9.8 \\
\hline Calcitic limestone & 7.7 & 6.4 \\
\hline Sodium chloride & 3.8 & 3.8 \\
Mineral-vitamin supplement ${ }^{1}$ & 1.0 & 0.9 \\
\hline L-lysine & 3.2 & 2.4 \\
\hline DL-methionine & 2.4 & 2.2 \\
\hline L-threonine & 0.9 & 0.5 \\
\hline Phytase & 0.05 & - \\
\hline Calculated analysis (g/kg, dry matter basis) & & \\
Crude protein & 176.5 & 176.0 \\
\hline Calcium & 6.1 & 6.1 \\
\hline Chlorine & 1.7 & 1.7 \\
Sodium & 1.9 & 1.9 \\
\hline Potassium & 5.8 & 5.8 \\
\hline Available phosphorus & 2.9 & 2.9 \\
\hline Digestible Met + Cys & 7.3 & 7.3 \\
\hline Digestible methionine & 5.2 & 4.6 \\
\hline Digestible lysine & 10.1 & 10.1 \\
\hline Digestible threonine & 6.5 & 6.5 \\
\hline Metabolizable energy (Mcal/kg) & 3.250 & 3.250 \\
\hline & & \\
\hline & &
\end{tabular}

${ }^{1}$ Guaranteed levels per kg product:vitamin A 10,000,000 IU; vitamin D3 4,000,000 IU; vitamin K3 3,500 mg; vitamin B1 2,500 mg; vitamin B2 6,000 mg; vitamin B6 4,000 mg; vitamin B12 20,000 mg; niacin 60 g; pantothenic acid 10 g; biotin 200 mg; manganese $70 \mathrm{~g}$; iron $50 \mathrm{~g}$; copper $10 \mathrm{~g}$; zinc $70 \mathrm{~g}$; iodine 1,200 mg. Mineral-vitamin supplement formulated with no inclusion of vitamin $\mathrm{E}$ and selenium.

In order to evaluate Se deposition in the breast muscle (Pectoralis major), birds were fed a basal diet not supplemented with Se or diets supplemented either with an inorganic Se source (sodium selenite, SS, containing $45 \%$ Se) or with an organic Se source (hydroxy-selenomethionine, HSM, containing 2\% Se) after 42 days of age.

In Experiment 1, at 42 days of age, 48 out of the 108 broilers were randomly selected and distributed according to a completely randomized experimental design into six treatments, with eight replicates of one bird each. The treatments consisted of a control basal diet not supplemented with Se (0); basal diet supplemented with SS at 200 (200 SS) or 400 (400 SS) $\mu \mathrm{g} / \mathrm{kg}$; and basal diet supplemented with HSM at 100 (100 HSM), 200 (200 HSM) or 300 (300 HSM) $\mu \mathrm{g} / \mathrm{kg}$. The premix did not contain any Se supplementation and the birds were fed with experimental feeds for 10 consecutive days.

Experiment 2 had a completely randomized design following a plot scheme subdivided in time, with three treatments and five replicates of four birds each. The 
Vieira V, Durau JF, Schramm VG, Bassi LS, Oliveira SG, Maiorka A Effect of Selenium Supplementation in Broiler Diets
on Breast Meat Deposition treatments consisted of the supply of a basal diet supplemented with $300 \mu \mathrm{gSS} / \mathrm{kg}$ (300 SS), the basal diet with $200 \mu \mathrm{gHSM} / \mathrm{kg}$ (200 HSM) or the basal diet supplemented with $100 \mu \mathrm{gSS} / \mathrm{kg}$ and $100 \mu \mathrm{gHSM} / \mathrm{kg}$ (100 SS+100 HSM). The premix did not contain any Se supplementation. 60 of the 108 broilers were fed the experimental diets for four periods $(3,6,9$ and 12 days) and sacrificed at the end of each period, at 45 , 48,51 and 54 days of age in order to determine breast meat Se content.

During both experiments, birds were offered feed and water ad libitum. The vitamin and mineral premix added to the experimental diets was free from selenium.

\section{Bird selection and sample collection}

The Se content of the breast muscle was analyzed in eight birds per treatment in Experiment 1 and five birds per treatment after each supplementation period described above in Experiment 2.

The birds were fasted for $6 \mathrm{~h}$ before sacrifice by electrical stunning and bleeding. Carcasses were scalded, plucked, manually eviscerated, and immersed in a chiller at $4^{\circ} \mathrm{C}$ for $60 \mathrm{~min}$. Carcasses were then cutup, and the breast was collected. Samples with $100 \mathrm{~g}$ average weight were collected from the cranial portion of the left Pectoralis major muscle. Each sample was duly identified, stored in a plastic bag, and freezedried.

Selenium content $(\mu \mathrm{g} / \mathrm{kg})$ in the experimental diets and muscle samples were determined in an atomic absorption spectrometer coupled to a graphite furnace (Unicam Solaar M6 Atomic Absorption Spectrometer, Unicam LTD, London, UK).

\section{Statistical analysis}

Experiment 1 had a completely randomized design and after applying Shapiro-Wilk test to verify the normality of the residues, all data were submitted to an one-way ANOVA and the means were compared by Tukey's test at 5\% probability level, using SAS statistical package (version 8, SAS Institute Inc., Cary, NC, USA), according to the statistical model:

$$
Y i j=\mu+\beta i+\varepsilon i j
$$

in which $Y_{i j}=$ observation $\mathrm{j}$ of experimental unit subjected to treatments $i, \mu=$ population mean, $\beta \mathrm{i}$ = effect of selenium sources supplementation on deposition in chicken meat, and $\varepsilon i j=$ random error associated to each observation.

Experiment 2 had a completely randomized design following a plot scheme subdivided in time. The data underwent a Shapiro-Wilk normality test and, after the initial assumptions were met, the factorial ANOVA was performed. Data with normal distribution were analyzed using the GLM procedure of SAS statistical package (version 8, SAS Institute Inc., Cary, NC, USA), according to the statistical model:

$$
Y i j k=\mu+\alpha i+\delta j k+\beta j+\alpha \beta i j+\varepsilon i j k
$$

in which Yijk = Value observed in the experimental unit that received level i of factor $A$ (selenium sources supplementation), with level $j$ of factor $B$ (days of supplementation) in repetition $\mathrm{K} ; \mu=$ mean of the observed variable; $\alpha i=$ effect of the $i^{\text {th }}$ factor $A ; \delta j k=$ experimental error of factor $A$ within plots; $\beta j=$ effect of the $j^{\text {th }}$ of factor $B ; \alpha \beta i j=$ interaction of factors $A$ and $B ; \varepsilon i j k=$ Experimental error $B$ within plots.

\section{RESULTS}

The results for analyzed dietary Se content show that the control diet (with no selenium inclusion) contained $32 \mu \mathrm{g} \mathrm{Se} / \mathrm{kg}$, which was possibly derived from the feedstuffs (Table 2).

Table $\mathbf{2}$ - Selenium sources and levels in the experimental diets.

\begin{tabular}{lcc}
\hline Se source & $\begin{array}{c}\text { Dietary Se inclusion level } \\
(\mu \mathrm{g} / \mathrm{kg})\end{array}$ & $\begin{array}{c}\text { Analyzed Se level } \\
(\mu \mathrm{g} / \mathrm{kg})\end{array}$ \\
\hline Experiment 1 & 0 & 32 \\
- & 200 & 87 \\
SS $^{1}$ & 400 & 277 \\
SS & 100 & 182 \\
HSM ${ }^{2}$ & 200 & 246 \\
HSM & 300 & 212 \\
\hline HSM & & \\
\hline Experiment 2 & 300 & 167 \\
\hline SS & 200 & 275 \\
HSM & $100+100$ & 404 \\
\hline SS+HSM & & \\
\hline
\end{tabular}

ISS: Sodium selenite (45\% Se);

${ }^{2}$ HSM: Hydroxy-selenomethionine (2\% Se).

In Experiment 1, muscle Se contents were significantly different among treatments $(p \leq 0.05)$ (Table 3). The highest Se breast content $(p<0.05)$ was obtained when birds were fed diets containing300 HSM, followed by the supplementation of 200 HSM, compared to the other treatments. However, no statistical differences ( $p>0.05)$ were observed among the birds fed the control diet and those containing sodium selenite (200 SS and 400 SS), or 100 HSM.

In Experiment 2, an interaction was observed between the days of Se supplementation and the Se sources ( $p<0.05$; Table 4$)$. Birds had a higher deposition of Se in breast muscle when fed diets with 200 HSM 
and $100 \mathrm{SS}+100 \mathrm{HSM}$ during 9 and 12 days $(p<0.05)$, compared to the birds fed diets supplemented with 300 SS in the same period. Feeding the birds for a shorter period with Se supplemented diets (3 and 6 days) resulted in lower levels of Se deposition, regardless of the utilized source.

Table 3 - Breast muscle selenium levels $(\mu \mathrm{g} / \mathrm{kg})$ of broilers fed the experimental diets for 10 days (Experiment 1).

\begin{tabular}{lc}
\hline Selenium source & Analyzed level $(\mu \mathrm{g} / \mathrm{kg})^{*}$ \\
\hline 0 & $58.86 \mathrm{a}$ \\
$200 \mathrm{SS}^{1}$ & $63.50 \mathrm{a}$ \\
$400 \mathrm{SS}^{2}$ & $80.13 \mathrm{a}$ \\
$100 \mathrm{HSM}^{3}$ & $88.50 \mathrm{a}$ \\
$200 \mathrm{HSM}^{4}$ & $126.43 \mathrm{~b}$ \\
$300 \mathrm{HSM}^{5}$ & $175.14 \mathrm{C}$ \\
$p$-value & $<0.001$ \\
SEM $^{6}$ & 6.621
\end{tabular}

"Means followed by different letters in the same column are statistically different by the test of Tukey at $5 \%$ significance level $(P<0.05)$.

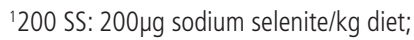

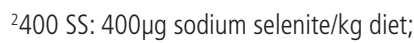

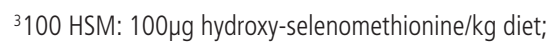

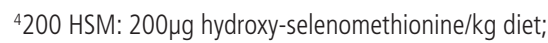

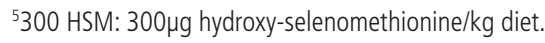

6SEM: Standard error of the mean.

Table 4 - Unfolding of the interaction between days of supplementation and selenium sources for breast muscle selenium levels in broilers fed the experimental diets for 12 days (Experiment 2).

\begin{tabular}{|c|c|c|}
\hline $\begin{array}{l}\text { Days of } \\
\text { supplementation }\end{array}$ & Selenium source & Analyzed Se level $(\mu \mathrm{g} / \mathrm{kg})^{\star}$ \\
\hline \multirow{3}{*}{3} & $300 S^{1}$ & $71.00 \mathrm{bc}$ \\
\hline & $200 \mathrm{HSM}^{2}$ & $86.20 b c$ \\
\hline & $100 \mathrm{SS}+100 \mathrm{HSM}^{3}$ & $78.00 \mathrm{bc}$ \\
\hline \multirow{3}{*}{6} & $300 \mathrm{SS}$ & $52.80 \mathrm{c}$ \\
\hline & $200 \mathrm{HSM}$ & $64.14 c$ \\
\hline & $100 \mathrm{SS}+100 \mathrm{HSM}$ & $67.72 \mathrm{c}$ \\
\hline \multirow{3}{*}{9} & $300 \mathrm{SS}$ & $68.22 b c$ \\
\hline & 200 HSM & $111.96 \mathrm{ba}$ \\
\hline & $100 \mathrm{SS}+100 \mathrm{HSM}$ & $89.50 \mathrm{ba}$ \\
\hline \multirow{3}{*}{12} & 300 SS & $71.80 \mathrm{~b}$ \\
\hline & 200 HSM & $101.36 \mathrm{a}$ \\
\hline & $100 \mathrm{SS}+100 \mathrm{HSM}$ & $101.50 \mathrm{a}$ \\
\hline $\mathrm{SEM}^{4}$ & & 2.557 \\
\hline \multirow[t]{3}{*}{$p$-value } & Day (D) & $<0.001$ \\
\hline & Source (S) & $<0.001$ \\
\hline & $D * S$ & 0.027 \\
\hline
\end{tabular}

*Means followed by different lowercase letters in the same column indicate statistical difference among by the test of Tukey at $5 \%$ significance level.

1300 SS: $300 \mu$ g sodium selenite/kg diet;

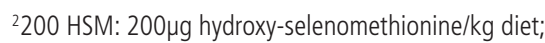

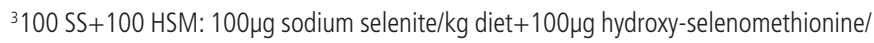
$\mathrm{kg}$ diet.

${ }^{4}$ SEM: Standard error of the mean.

\section{DISCUSSION}

The results of the present study are consistent with the findings of Briens et al. (2013), who evaluated Se breast muscle deposition in broilers fed diets with SS, Se yeast (SY), and HSM at different doses. Those authors observed higher Se breast deposition as Se dose increased, with the highest level obtained with HSM source. The authors assigned this result to the $39 \%$ higher bioavailability of HSM compared with SY.

Many studies report superior effects of supplementation of organic sources of Se in broiler feeds, compared to inorganic sources. Oliveira et al. (2014) obtained higher Se deposition in the breast muscle of broilers fed an organic Se (selenized yeasts) compared with those fed inorganic or combined inorganic and organic sources. Pappas et al. (2012) also had positive results when feeding selenized yeast to broilers, improving broiler meat quality and reducing the oxidation of long-chain fatty acids in breast muscle. Such results associated to organic Se sources can be explained by O'Dell \& Sunde (1997), which describe selenized yeast containing $40-70 \% \mathrm{Se}$ as selenomethionine, with an absorption rate of $98 \%$ in the small intestine, where Se is actively absorbed.

Briens et al. (2014) explained that when included at $2 \%$ of the diet, HSM, which is a selenomethionine analogue, is $100 \%$ metabolized into selenocysteine and selenomethionine, resulting in higher Se levels in muscle compared to when broilers are fed selenized yeast. The same happens in different tissues, as similar results regarding selenomethionine supplementation were observed for Se deposition in the liver (Jlali et al., 2014) and breast meat (Silva et al., 2019) of broilers.

Couloigner et al. (2015) stated that Se muscle deposition is an effective measure of the kinetics of Se deposition in broiler tissues. The authors also reported higher efficiency of Se deposition in the breast muscle when birds were fed organic Se sources (HSM and SY) compared with sodium selenite. In the present study, the diets containing organic Se as HSM at 2\%, alone or in combination with selenium selenite, also resulted in higher rates of breast muscle Se deposition compared to the diet containing only inorganic Se.

The dietary supplementation of $200 \mathrm{HSM}$ for 10 and 9 days in experiments 1 and 2, respectively, resulted in the deposition of $12.64 \mu \mathrm{g}$ (Experiment 1) and $11.96 \mu \mathrm{g}$ (Experiment 2) Se per $100 \mathrm{~g}$ of breast muscle. These results indicate that the consumption of $150 \mathrm{~g}$ of this Se-enriched chicken meat would closely match the Se requirements of children between 1 and 
3 years of age (20 $\mu \mathrm{g}$ Se/day), according to the IOM (2000). The Guidance for Compliance with European Regulation (EC) NO.1925/2006 (2011), defined by the Food Labeling Directive 90/496/EEC, determines that, in order to claim health benefits and to be labeled as a vitamin or mineral "source", $100 \mathrm{~g}$ of a food item must contain $15 \%$ of the Recommended Daily Allowance (RDI) of that particular vitamin or mineral. In Brazil, a study showed low Se intake of 3- and 7-year-old children living in areas where food crops have low Se levels (Maihara et al., 2004). According to Martens et al. (2015), the consumption of Se-enriched foods may improve Se status in humans, which suggests that the consumption of Se-enriched chicken meat may be an alternative to increase Se status. Moreover, Fleet (1997) found higher cancer incidence in regions of the United States where the soil was poor in selenium and emphasized the need of further research to investigate the role of $\mathrm{Se}$ intake in the prevention of cancer. More recent studies (Tanguy et al., 2012; Kumar \& Priyadarsini, 2014) demonstrated health benefits of Se intake both for the prevention and reduction of the incidence of several disorders and severe diseases.

\section{CONCLUSIONS}

Selenium may be supplemented in broiler diets to increase Se deposition in the breast muscle, by using other sources to complement Se levels in trace mineral premix. The supplementation of broiler diets with hydroxy-selenomethionine at $2 \%$ for a short period is more efficient to increase selenium deposition in the breast muscle than sodium selenite. Increasing Se content in breast meat of broilers is an efficient way to guarantee the dietary intake requirements of this micronutrient for human consumption.

\section{REFERENCES}

Briens M, Mercier Y, Rouffineau F, Mercerand F, Geraert PA. 2-Hydroxy4-methyl seleno butanoic acid induces additional tissue selenium enrichment in broiler chickens compared with other selenium sources. Poultry Science 2014;93(1):85-93.

Briens M, Mercier Y, Rouffineau F, Vacchina V, Geraert, PA. Comparative study of a new organic selenium source v. seleno-yeast and mineral selenium sources on muscle selenium enrichment and selenium digestibility in broiler chickens. British Journal of Nutrition 2013;110(4):617-624.

Colpo E, Vilanova CDDA, Brenner Reetz LG, Medeiros MMFD, FariasI LG, Irineu EM, et al. A single consumption of high amounts of the Brazil nuts improves lipid profile of healthy volunteers. Journal of Nutrition and Metabolism 2013;2013:1-7

Combs GF. Selenium in global food systems. British Journal of Nutrition 2001;85(5):517-547
Cominetti C, Bortoli MC, Garrido Jr A, Cozzolino SM. Brazilian nut consumption improves selenium status and glutathione peroxidase activity and reduces atherogenic risk in obese women. Nutrition Research 2012;32(6):403-407.

Couloigner F, Jlali M, Briens M, Rouffineau F, Geraert PA, Mercier Y. Selenium deposition kinetics of different selenium sources in muscle and feathers of broilers. Poultry Science 2015;94(11):2708-2714.

Fairweather-Tait SJ, Collingsand R, Hurst R. Selenium bioavailability: current knowledge and future research requirements. American Journal of Clinical Nutrition 2010;91(5):1484S-1491S.

Fleet JC. Dietary selenium repletion may reduce cancer incidence in people at high risk who live in areas with low soil selenium. Nutrition Reviews 1997;55(7):277-279.

Fortified Foods. Guidance to compliance with European Regulation (EC) No. $1925 / 2006$ on the addition of vitamins and minerals and certain other substances to food. London: Department of Health;2018.

IOM - Institute of Medicine. Dietary references intakes for vitamin C, vitamin $\mathrm{E}$, selenium and carotenoids. Washington: National Academic Press; 2000

Jlali M, Briens M, Rouffineau F, Geraert PA, Mercier Y. Evaluation of the efficacy of 2-hydroxy-4-methylselenobutanoic acid on growth performance and tissue selenium retention in growing pigs. Journal of Animal Science 2014;92(1):182-188.

Kumar BS, Priyadarsini KI. Selenium nutrition: How important is it? Biomedicine and Preventive Nutrition 2014;4(2):333-341.

Maihara VA, Gonzaga IB, Silva VL, Fávaro DIT, Vasconcellos MBA, Cozzolino SMF. Daily dietary selenium intake of selected Brazilian population groups. Journal of Radioanalytical and Nuclear Chemistry 2004:259(3):465-468

Martens IB, Cardoso BR, Hare DJ, Niedzwiecki MM, Lajolo FM, Martens $A$, et al. Selenium status in preschool children receiving a Brazil nutenriched diet. Nutrition 2015;31(11-12):1339-1343.

O'Dell BL, Sunde RA. Handbook of nutritionally essential mineral elements. $2^{\text {nd }}$ ed. New York: Marcel Dekke; 1997.

Oliveira TFB, Rivera DFR, Mesquita FR, Braga H, Ramos EM, Bertechini AG. Effect of different sources and levels of selenium on performance, meat quality, and tissue characteristics of broilers. Journal of Applied Poultry Research 2014;23(1):15-22.

Pappas AC, Zoidis E, Papadomichelakis G, Fegeros K. Supranutritional selenium level affects fatty acid composition and oxidative stability of chicken breast muscle tissue. Journal of Animal Physiology and Animal Nutrition 2012;96(3):385-394.

Rayman MP. Food-chain selenium and human health: emphasis on intake. British Journal of Nutrition 2008;100(2):254-268.

Rostagno H, Albino LFT, Donzele JL, Gomes PC, Oliveira RD, Lopes DC, et al. Tabelas Brasileiras para Aves e Suínos: Composição de Alimentos e Exigências Nutricionais. $3^{\text {rd }}$ ed. Viçosa: Universidade Federal de Viçosa; 2011.

Silva VA, Clemente AHS, Nogueira BRF, Carvalho AC, Freitas LFVB, Souza $A L S$, et al. Supplementation of seleniomethionine at different ages and levels on meat quality, tissue deposition, and selenium retention in broiler chickens. Poultry Science 2019;98(5):2150-2159.

Stockler-Pinto MB, Malm O, Moraes C, Farage NE, Silva WS, Cozzolino SM, et al. A follow-up study of the chronic kidney disease patients treated with Brazil nut: focus on inflammation and oxidative stress. Biological Trace Element Research 2015;163(1-2):67-72. 
Szymonik-Lesiuk S, Czechowska G, Stryjecka-Zimmer M, Łomka MS, Mądro A, Celinski K, et al. Catalase, superoxide dismutase, and glutathione peroxidase activities in various rat tissues after carbon tetrachloride intoxication. Journal of Hepato-Biliary-Pancreatic Surgery 2003;10(4):309-315

Tanguy S, Grauzam S, Leiris J, Boucher F. Impact of dietary selenium intake on cardiac health: experimental approaches and human studies. Molecular Nutrition and Food Research 2012;56(7):1106-1121.

Waegeneers N, Thiry C, Temmerman L, Ruttens A. Predicted dietary intake of selenium by the general adult population in Belgium. Food Additives \& Contaminants: Part A 2013;30(2):278-285. 